\title{
A CONSTRUÇÃO HISTÓRICA DO CONHECIMENTO DA ENFERMAGEM GERONTOLOGICA NO BRASIL
}

\author{
The historical construction of gerontological nursing knowledge in brazil \\ La construcción histórica del conocimiento de la enfermería gerontológica en brasil
}

\author{
Denise Faucz Kletemberg ${ }^{1}$ \\ Míriam Süsskind Borenstein ${ }^{4}$
}

\author{
Maria Itayra Padilha \\ Ângela Maria Alvarez ${ }^{5}$
}

Lúcia Hisako Takase Gonçalves ${ }^{3}$

Aline Coelho Ferreira ${ }^{6}$

\section{RESUMO}

Este estudo tem como objetivo historicizar a construção da produção do conhecimento em Enfermagem Gerontológica no Brasil. É um estudo sócio-histórico, com abordagem qualitativa, sob o referencial teórico de Eliot Freidson, que relaciona conhecimento ao poder profissional. É um estudo exploratório qualitativo descritivo documental. Utilizou como fontes bases de dados eletrônicas. Nos resultados encontramos 473 pesquisas a partir da década de 1970 até março de 2010; 39 grupos de pesquisa, sendo 8 com especificidade no estudo sobre o idoso e 31 que contêm, entre suas linhas de pesquisa, o estudo do envelhecimento humano. Conclui-se que o escopo da produção científica em enfermagem sobre o processo de envelhecimento e o número crescente de grupos de estudos interessados nessa temática refletem os avanços teórico-metodológicos desse conhecimento especializado.

Palavras-chave: História da Enfermagem. Saúde do Idoso. Pesquisa em Enfermagem. Gerontologia

\begin{abstract}
This research is aimed to the production of knowledge in Gerontological Nursing in Brazil. It is a socio-historical research with a qualitative approach using Eliot Freidson as the reference author. It is an exploratory, qualitative, descriptive and documental study. Electronic databases were used as research sources. Listed in this search were collected 473 articles from the 1970s decade until March 2010 and 39 research groups, 8 with specificity in the study of the elderly and 31 that have the study of human aging as an approach line. We concluded that the scope of scientific production in nursing about the aging process and the growing number of groups of studies investigating this issue, reflect the theoretical and methodological improvement in that specialized knowledge.
\end{abstract}

Keywords: History of nursing. Health of the Elderly. Nursing Research

\section{Resumen}

El objetivo del presente estudio es historizar la construcción de la producción del conocimiento en Enfermería Gerontológica en Brasil. Se trata de un estudio socio-histórico, exploratorio y descriptivo, con enfoque cualitativo, desde el marco teórico de Eliot Freidson, autor que relaciona el conocimiento al poder profesional. Los datos fueron recolectados de bases de datos electrónicas. En los resultados se encontraron 473 investigaciones realizadas desde la década de setenta hasta marzo de 2010; 39 grupos de investigación, 8 con estudios específicos sobre los ancianos y 31 que contienen en su área de investigación, estudios sobre el envejecimiento humano. Se concluye que el ámbito de la producción científica de enfermería sobre el proceso de envejecimiento y el creciente número de grupos de estudio sobre este tema, reflejan los avances teóricos e metodológicos de ese conocimiento.

Palabras clave: Historia de la Enfermería. Salud del Anciano. Investigación en Enfermería

\footnotetext{
${ }^{1}$ Enfermeira. Bolsista CAPES. Doutoranda do Programa de Pós-graduação em Enfermagem da Universidade Federal de Santa Catarina. Integrante do Grupo de Estudos da História do Conhecimento em Enfermagem e Saúde-GEHCES. Florianópolis-SC. Brasil. E-mail: denisekle@yahoo.com.br² Enfermeira. Professora do Departamento de Enfermagem da UFSC. Doutora em Enfermagem pela Escola Anna Nery da Universidade Federal do Rio de Janeiro. Pós-Doutora pela Lawrence Bloomberg Faculty of Nursing at University of Toronto/Canada. Coordenadora do GEHCES. Pesquisadora do CNPq. Florianópolis-SC. Brasil. E-mail: padilha@nfr.ufsc.br ${ }^{3}$ Enfermeira. Professora do Departamento de Enfermagem da UFSC. Doutora em Enfermagem pela USP/SP. Pós-Doutora pela University of Califórnia USA. Pesquisadora do CNPq. Florianópolis-SC. Brasil. E-mail: lucia@nfr.ufsc.br, ${ }^{4}$ Enfermeira. Professora do Departamento de Enfermagem. Doutora em Filosofia da Enfermagem PEN - UFSC. Vice-Líder do GEHCES. Pesquisadora do CNPq. Florianópolis-SC. Brasil. E-mail: miriam@nfr.ufsc.br ${ }^{5}$ Enfermeira, Doutora, Professora do Departamento de Enfermagem da UFSC. Coordenadora do Núcleo de Estudos da Terceira Idade/UFSC. Florianópolis-SC. Brasil. E-mail: angela@nfr.ufsc.br6raduanda de Enfermagem da UFSC, Bolsista de Iniciação Científica CNPq. Integrante do GEHCES. Florianópolis-SC. Brasil. E-mail: alineferreiraufsc@yahoo.com.br
} 


\section{INTRODUÇÃO}

A enfermagem brasileira congruente com os movimentos políticos e sociais mundiais sobre o envelhecimento populacional a partir de meados do século XX, e pela transição demográfica do envelhecimento, foi impulsionada a desenvolver estudos para o atendimento às especificidades do idoso. Esses esforços se intensificaram nas últimas três décadas, concomitantemente ao Plano Internacional de Ação para o Envelhecimento, em 1982, e mais significativamente com a promulgação da Política Nacional do Idoso, em 1996.

Essa constatação está fundamentada em pesquisa sobre as dissertações e teses de enfermagem sobre o idoso, a partir das quais se verificaram picos de produção coincidentes aos períodos de maior discussão sobre o tema no Brasil, que foram aqueles em que as Leis e Políticas Federais foram efetivadas. ${ }^{1}$ 0 interesse por essa população deu-se pela combinação entre o aumento proporcional do número de idosos na população do país, a criação das leis específicas para garantir os direitos dos idosos e 0 incentivo para instituir o ensino de Geriatria e Gerontologia nas universidades, que impactou no incremento da produção científica em enfermagem.

Os primeiros esforços para o estudo do envelhecimento em enfermagem no Brasil datam da década de 1970, com produções esparsas e a criação do primeiro Grupo de Pesquisa em Enfermagem, o NESPI da Universidade Federal da Bahia, em 1973. ${ }^{2}$ A partir da década de 1980, ocorreu uma produção científica pequena, porém continuada, principalmente no meio acadêmico em programas de pós-graduação em nível de especialização, mestrado e doutorado. ${ }^{3}$

0 desenvolvimento dos estudos e 0 aumento quantitativo dos pesquisadores em enfermagem gerontológica permitiram, em 1996, a realização da I Jornada Brasileira de Enfermagem Geriátrica e Gerontológica, em Florianópolis, ${ }^{3} \mathrm{e}$ em 2010 alcançou sua oitava edição, no Rio de Janeiro. Na contemporaneidade, a atenção à saúde do idoso e seus familiares é uma questão que vem sendo discutida por um grupo cada vez maior de profissionais da área da saúde. Esse interesse se deve à tomada de consciência desses profissionais acerca de seu papel em um contexto de generalizada carência de recursos sociais e de saúde, e de profissionais para assistir a essa clientela. ${ }^{4}$

Essa procura pelo conhecimento é explicada por Eliot Freidson como busca pelo poder profissional. Para esse sociólogo, as profissões, para alcançarem o reconhecimento social, buscam o conhecimento especializado na educação superior e a consequente autonomia de seu processo de trabalho, para deter o poder profissional sobre uma ocupação. ${ }^{5} 0$ conhecimento, como meio para preservar o controle sobre 0 mercado de trabalho e o modo de transmissão desse conhecimento, é foco de reflexão de Freidson. Para o autor, nenhum dos métodos de controlar a prática das qualificações e os termos de seu emprego é tão efetivo como o método viabilizado pelo ensino das profissões. Um corpo docente com dedicação deve ter tempo para refinar, revisar e codificar o corpo de conhecimento, bem como criar novos elementos. ${ }^{5}$ Essa refinação e elaboração de novos conhecimentos tem o propósito de instrumentalizar os profissionais no atendimento qualificado à população idosa, dando o embasamento científico necessário para a construção dessa especialidade.

A relevância do saber para o poder ou status profissional fomentou este estudo, que tem como objetivo refletir sobre a construção histórica da produção do conhecimento em enfermagem gerontológica no Brasil, a partir de 1970 até 0 presente. Para o alcance desse objetivo, foi necessária a análise do desenvolvimento das pesquisas e dos grupos de pesquisa de enfermagem sobre o processo de envelhecimento, contextualizada com o período histórico dessas publicações.

\section{METODOLOGIA}

Trata-se de uma pesquisa sócio-histórica documental, com abordagem qualitativa. A pesquisa histórica traz contribuição significativa para a enfermagem, remete os profissionais a uma visão crítica dos constituintes sociopolíticos e culturais que entremearam a constituição dela como profissão. Essa percepção propicia uma amplitude de análise desses fatores e permite a visualização e compreensão dos avanços e das dificuldades encontradas nessa construção. ${ }^{6}$ Foram utilizadas duas fontes documentais: A primeira foram os bancos de dados eletrônicos LILACS (Literatura Latino-Americana e do Caribe em Ciências da Saúde); SciELO (Scientific Eletronic Library Online), BDENF (Banco de Dados de Enfermagem) e o CEPEn/ABEn (Centro de Estudos e Pesquisa em Enfermagem, da Associação Brasileira de Enfermagem), com os descritores: idoso, gerontologia, velhice. Foram elencados pelo banco de dados on-line 473 estudos de pesquisa no período de 1970 até março de 2010. Cabe aqui ressaltar que esse número não reflete rigorosamente a realidade, pois, devido às falhas de indexação por diversos motivos, outros estudos provavelmente não foram incluídos nos estudo. Para facilitar a análise dos dados, os trabalhos foram identificados e separados segundo as décadas nas quais foram publicados, o que possibilitou a contextualização histórica dos fatos e da produção do conhecimento.

A segunda fonte de dados foi o Diretório de Grupos de Pesquisa no Brasil, do CNPq, em base corrente, para identificar os Grupos de Pesquisa sobre o processo de envelhecimento no Brasil. Os termos de busca foram a associação da palavra enfermagem com as variantes do processo de envelhecimento, como: idoso; envelhecimento; gerontologia; geriatria; velhice. Para inclusão do grupo, foram utilizados como critério os termos das variantes do processo de envelhecimento como palavraschave na descrição da linha de pesquisa do grupo. Assim, nessa listagem estão grupos que não têm como foco principal o idoso, mas que possuem, em uma ou mais de suas linhas de pesquisa, 
o envelhecimento como objeto possível de estudo. Foram elencados 39 grupos de pesquisa, sendo oito com especificidade no estudo sobre o idoso e 31 que possuem, dentre suas linhas de pesquisa, o estudo do envelhecimento humano. Após a coleta de dados, estes foram agrupados pelas semelhanças elencadas através das palavras-chave selecionadas anteriormente e foram formadas duas categorias de análise. São elas: A pesquisa em enfermagem gerontogeriátria e 0 s grupos de pesquisa em enfermagem gerontogeriátrica.

0 presente estudo não necessitou ser submetido ao Comitê de Ética da Universidade Federal de Santa Catarina, por tratar-se de uma pesquisa documental, e ter utilizado apenas fontes de domínio público para sua concretização, porém os pesquisadores seguiram rigorosamente os cuidados éticos na busca, análise e discussão dos resultados.

\section{RESULTADOS E DISCUSSÃO}

\section{A PESQUISA EM ENFERMAGEM GERONTOGERIÁTRICA}

A busca pelo conhecimento, a expertise, é reconhecida por Eliot Freidson como instrumento de poder profissional. Uma das frases citadas em seu livro Renascimento do profissionalismo que chama a atenção para o presente estudo é: " 0 conhecimento em si não dá poder especial: somente o conhecimento exclusivo dá poder a seus detentores". 5:104E essa busca pelo conhecimento exclusivo acaba por determinar as especializações dentro das profissões. Esse discurso do monopólio do saber profissional é vivenciado na contemporaneidade pela enfermagem, que busca no conhecimento científico delimitar seu espaço na área da saúde, desenvolvendo e criando novas especializações que deem conta da amplitude do saber.

0 direcionamento para a resolução dos problemas enfrentados pelos idosos compõe o discurso dos profissionais da enfermagem na área de gerontologia e exige o desenvolvimento de conhecimentos e ações que deem suporte e subsídios para o suprimento das necessidades dos indivíduos dessa faixa etária e contribuam para a formação dos profissionais envolvidos. ${ }^{7}$ Assim, para compreender a evolução histórica do conhecimento em enfermagem gerontológica no Brasil é imperioso que se proceda à análise das pesquisas desenvolvidas, que retratam o caminhar dessa especialidade, contextualizada na realidade mundial e nacional do interesse pelo estudo do envelhecimento humano.

0 direcionamento para o desenvolvimento de pesquisas em enfermagem na área do envelhecimento vem ocorrendo desde 1904, data da publicação do primeiro artigo de enfermagem sobre o cuidado ao idoso, no American Jounal of Nursing, o qual apresentava muitos dos princípios que orientam a prática da enfermagem gerontológica nos dias atuais. ${ }^{8}$ Esse dado coincide cronologicamente com 0 início das pesquisas sobre 0 processo de envelhecimento e com a criação do termo "gerontologia" por Elie Metchnikoff, em 1903. ${ }^{9}$ Reflete, assim, a participação da enfermagem desde os primórdios do desenvolvimento dos estudos sobre o idoso e faz dessa profissão coparticipante na institucionalização dessa área do conhecimento.

Vários obstáculos tiveram de ser transpostos pelas enfermeiras para o desenvolvimento desses estudos. Um deles foi o preconceito experenciado pelas pioneiras nessa área. As enfermeiras geriátricas eram consideradas inferiores em sua capacidade, como aquelas que não detinham conhecimento para o cuidado imediato. Os salários baixos e as condições das instalações geriátricas podem ter desencorajado o desenvolvimento inicial dessa especialidade. Havia uma percepção negativa dela nos programas educacionais, nos quais as experiências com idosos eram inadequadas, focadas nas patologias, e não nos idosos sadios que representavam a maioria da população. ${ }^{8}$

Nas duas últimas décadas do século XX, a enfermagem procurou superar as limitações do modelo tradicional da ciência e, mais especificamente, do modelo biomedicomecanicista dominante na atenção à saúde. Essa mudança fez surgir um cuidado mais subjetivo, com significado pessoal, que enfrentava a diversidade das situações do cotidiano e passou a valorizar o estar junto com o outro, o buscar conhecer o outro com suas diferenças sociais e culturais. ${ }^{10}$

Na década de 1970 houve produção esparsa de trabalhos em enfermagem gerontológica. ${ }^{11} 0$ quantitativo reduzido, aliado às dificuldades de indexação das produções daquela década, ficou estampado na coleta de dados, quando cronologicamente a busca eletrônica não computou trabalho nessa década. Cabe ressaltar que essa ausência apenas confirma dados da escassez de pesquisas publicadas.

A produção científica da enfermagem sobre o idoso se manteve pequena na década de 1980. No levantamento realizado nas bases de dados relativas à produção científica em periódicos e no Banco de Teses do CEPEN foram encontrados 21 trabalhos, sendo uma tese de livre-docência, seis dissertações de mestrado e 14 artigos em revistas científicas. Cabe novamente salientar que esse quantitativo não expressa com fidedignidade a produção científica da enfermagem brasileira daquela década, devido às dificuldades de indexação desses trabalhos mais remotos. No entanto, observam-se indícios de que se iniciava um fomento às pesquisas. Esse fato se justifica por ser essa a década do início do debate sobre o processo de envelhecimento em nível mundial. 
A década de 1980 trouxe mudanças representativas na gerontologia brasileira, consequências do Plano Internacional de Ação para o Envelhecimento de 1982, que impeliu a conscientização da necessidade dos países de incorporar em seus planos propostas de ações que garantissem um envelhecimento saudável. Um dos reflexos dos novos rumos foi o capítulo referente às questões sociais do texto constitucional de 1988, que coincidiu com o movimento de redemocratização no país. A partir dessa assembleia ocorrida em Viena, os países com uma grande população jovem e em desenvolvimento, como o Brasil, a China e Índia, foram chamados a refletir sobre o impacto do envelhecimento populacional em suas sociedades nas próximas décadas e a necessidade de desenvolver políticas de apoio à velhice.

Percebe-se aumento quantitativo de trabalhos a partir de meados dessa década, com destaque para 1985, ano em que foram defendidas quatro dissertações de mestrado sobre a temática. Esse número aponta o início da produção científica vinculada aos programas de pós-graduação no país de forma mais impactante e demonstra o interesse dos docentes pesquisadores pela temática que se configurava na agenda mundial. Dados do BDENF apontam a defesa da primeira tese de livre-docência sobre idoso, em 1989, pela Profa. Maria Coeli Campedelli, intitulada: Consulta de enfermagem em geriatria: proposta de modelo.

Com base nas diretrizes dispostas na Constituição de 1988, foi aprovada a Lei n. 8842, de 1994, da Política Nacional do Idoso, regulamentada pelo Decreto $n^{\circ} .1948 /$ 96, que assegurava direitos sociais à pessoa idosa, criava condições de promover sua autonomia, integração e participação efetiva na sociedade e reafirmava seu direito à saúde nos diversos níveis de atendimento do SUS. ${ }^{12}$ Nesse contexto o quantitativo de trabalhos publicados sobre 0 processo de envelhecimento na área da enfermagem teve discreto aumento, quando foram encontrados 71 trabalhos, com destaque para os três últimos anos da década de 1990. No ano seguinte à publicação da Política Nacional do Idoso, constatou-se um aumento significativo na publicação de trabalhos (19 trabalhos), número que se manteve nos anos seguintes.

Se até então houve aumento pequeno, porém constante na produção científica de enfermagem sobre o processo de envelhecimento, a virada do século XXI assistiu a uma explosão quantitativa no número de trabalhos. Foram 381, divididos de forma mais equânime durante os primeiros anos da década, com acréscimo acentuado a partir de 2004, com 45 trabalhos, 2005, com 41, 2006, com 45, 2007, com 38, 2008, com 57, e 2009, com 21. Esse acréscimo acentuado ocorreu devido a: expansão histórica dos programas de mestrado e doutorado iniciada na década anterior, da realização da Segunda Assembleia Mundial de Madri, em 2002, e da promulgação no Brasil do Estatuto do Idoso em 2003.

Pesquisa realizada para a análise das dissertações e teses de Enfermagem sobre idoso, realizadas no Brasil entre 1979 e 2004, ${ }^{1}$ aponta que dos 74 estudos desenvolvidos sobre idosos entre 1999 e 2004, houve maior número de estudos no ano de 1999, com o total de 15, sendo 10 dissertações e cinco teses de doutorado. Em 2000, a Enfermagem brasileira produziu 14 estudos, sendo 13 dissertações e uma tese. Em 2001, as 11 pesquisas desenvolvidas foram realizadas por mestrandos. Já em 2002, 11 dissertações e três teses foram desenvolvidas, do total de 14 estudos. Com relação aos temas de investigação das teses e dissertações analisadas no mesmo trabalho, identificou-se predomínio de pesquisas sob a ótica do idoso como paciente, nas quais os autores tentavam avaliar algum aspecto relevante a sua doença ou à hospitalização. Em menor escala, houve estudos sobre medicina preventiva; a preocupação com a qualidade de vida; saúde mental da pessoa idosa; e o autocuidado. Pesquisas sobre ética e a promoção do desenvolvimento social, político ou intelectual dos idosos não foram evidenciadas na análise das autoras, as quais concluíram que existem lacunas importantes na produção de conhecimento sobre a população idosa na enfermagem brasileira.

Esses dados coincidem com outra pesquisa bibliográfica realizada para analisar a produção científica sobre o idoso na Revista Brasileira de Enfermagem ${ }^{13}$, no período de 2000 a 2006, que trouxe como achados: maior concentração da quantidade da produção científica a partir de 2004; maioria de pesquisas com abordagem qualitativa; concentração da produção científica na região sudeste do país, com predominância de autores doutores e quase em sua totalidade ligados a programas de pós-graduação stricto sensu.

0 número reduzido de trabalhos na perspectiva da promoção da saúde ao idoso está confirmado também no levantamento dos trabalhos apresentados nos Congressos Brasileiros de Enfermagem, entre 1998 e 2002. ${ }^{14}$ Dentre os 285 trabalhos elencados na área da saúde do idoso, apenas três trataram do idoso sob uma perspectiva de grupo para promoção da saúde e 22 ainda enfatizaram os grupos de autoajuda como estratégia para atividade de educação em saúde, principalmente para controle de doenças crônico-degenerativas.

0 volume de estudos encontrados aponta crescimento vertiginoso da produção científica da 
Enfermagem em Gerontologia, em especial na virada do século XXI, o que confirma a consolidação da pesquisa nessa área. Para Freidson, o desenvolvimento da expertise é fundamental para estabelecer a autoridade em coordenar a divisão de trabalho de uma profissão. ${ }^{5}$ Dessa maneira, a enfermagem brasileira vem caminhando a passos largos para a fundamentação de um corpo de conhecimento especializado que dê respaldo científico para a institucionalização dessa área como especialidade da enfermagem.

\section{OS GRUPOS DE PESQUISA EM ENFERMAGEM GERONTOGERIÁTRICA}

A análise dos trabalhos publicados em enfermagem sobre o processo de envelhecimento remete, quase que obrigatoriamente, à análise também da criação dos grupos de pesquisa no país. Sendo eles responsáveis diretos pelo fomento à produção científica, faz-se necessário aqui historicizá-los, buscando-se contextualizá-los nos constituintes históricos que permearam a construção da especialidade da enfermagem gerontológica. Nesse sentido, identificamse duas categorias de grupos envolvidos em estudos relativos ao idoso. No primeiro, foram incluídos os oito grupos que tinham no próprio título a especificidade do cuidado ao idoso, que será apresentado no primeiro quadro. No segundo foram incluídos os 31 grupos restantes, cujas linhas de pesquisa também focam 0 processo de envelhecimento.

Quadro 1 - Grupos de Pesquisa em Enfermagem com especificidade na saúde do Idoso. Florianópolis, 2010

\begin{tabular}{|c|c|c|c|}
\hline $\begin{array}{l}\text { Ano de } \\
\text { criação }\end{array}$ & Nome do grupo & Instituição & Linhas de pesquisa \\
\hline 1973 & $\begin{array}{l}\text { NESPI- Núcleo de } \\
\text { Estudos e Pesquisas do } \\
\text { Idoso }\end{array}$ & UFBA & $\begin{array}{l}\text { Atenção à Saúde do Idoso; Ética na Saúde } \\
\text { e Enfermagem; Família e Assistência } \\
\text { Domiciliar; Informação e Comunicação } \\
\text { na Assistência ao Idoso; Violência e } \\
\text { Saúde do Idoso. }\end{array}$ \\
\hline 1982 & $\begin{array}{l}\text { GESPI- Grupo de } \\
\text { Estudos sobre Cuidado } \\
\text { de Saúde de Pessoas } \\
\text { Idosas }\end{array}$ & UFSC & $\begin{array}{l}\text { Arte, criatividade e tecnologia em saúde e } \\
\text { enfermagem; Cuidado e processo de } \\
\text { viver, ser saudável e adoecer; Educação, } \\
\text { saúde e enfermagem. }\end{array}$ \\
\hline 1985 & $\begin{array}{l}\text { NUPEGG - Núcleo de } \\
\text { Pesquisa de } \\
\text { Enfermagem Geriátrica } \\
\text { e Gerontológica }\end{array}$ & USP & $\begin{array}{l}\text { Educação em saúde; O processo de cuidar } \\
\text { do adulto com doenças crônicas; Saúde do } \\
\text { idoso. }\end{array}$ \\
\hline 1997 & $\begin{array}{l}\text { Grupo de A tenção à } \\
\text { Saúde do Idoso }\end{array}$ & UNICAMP & $\begin{array}{l}\text { O processo de cuidar em saúde e } \\
\text { enfermagem; Qualidade de vida na } \\
\text { velhice e educação; Saúde do idoso. }\end{array}$ \\
\hline 2004 & $\begin{array}{l}\text { GEP-GERON -Grupo } \\
\text { de Estudo e Pesquisa em } \\
\text { Gerontogeriatria, } \\
\text { Enfermagem/Saúde e } \\
\text { Educação. } \\
\end{array}$ & FURG & Tecnologia em saúde e enfermagem \\
\hline 2004 & $\begin{array}{l}\text { GMPI - Grupo } \\
\text { Multiprofissional de } \\
\text { Pesquisa sobre Idosos }\end{array}$ & UFPR & $\begin{array}{l}\text { Políticas e Práticas de Saúde, Educação e } \\
\text { Enfermagem; Processo de cuidar em } \\
\text { saúde e enfermagem; Saúde e Qualidade } \\
\text { de Vida }\end{array}$ \\
\hline 2007 & $\begin{array}{l}\text { NEPEG - Núcleo de } \\
\text { Estudos e Pesquisas em } \\
\text { Enfermagem } \\
\text { Gerontológica }\end{array}$ & UFF & $\begin{array}{l}\text { O cuidado de enfermagem ao idoso e sua } \\
\text { rede cuidadora; O idoso no contexto da } \\
\text { saúde e da sociedade; Saberes e práticas } \\
\text { da enfermagem gerontológica }\end{array}$ \\
\hline 2007 & $\begin{array}{l}\text { GIEPERS - Grupo } \\
\text { Internacional de Estudos } \\
\text { e Pesquisas sobre } \\
\text { Envelhecimento e } \\
\text { Representações Sociais }\end{array}$ & UFPB & $\begin{array}{l}\text { Epidemiologia e saúde; Políticas e } \\
\text { práticas em saúde e Enfermagem; } \\
\text { Trabalhos e políticas públicas. }\end{array}$ \\
\hline
\end{tabular}


A História da enfermagem gerontológica no Brasil

Quadro 2 - Grupos de Pesquisa em Enfermagem com linhas de pesquisa que também focam o processo de envelhecimento. Florianópolis, 2010

\begin{tabular}{|c|c|c|c|}
\hline $\begin{array}{l}\text { Ano de } \\
\text { criacão }\end{array}$ & Nome do grupo & Instituição & Linhas de pesquisa \\
\hline 1995 & $\begin{array}{l}\text { Núcleo de Enfermagem } \\
\text { em Oncologia }\end{array}$ & UNIFESP & $\begin{array}{l}\text { Fundamentos e práticas da enfermagem na } \\
\text { saúde do adulto e idoso }\end{array}$ \\
\hline 1997 & $\begin{array}{l}\text { GEPSAE - } \\
\text { Sistematização da } \\
\text { Assistência de } \\
\text { Enfermagem }\end{array}$ & UNIFESP & $\begin{array}{l}\text { Fundamentos e práticas de Enfermagem } \\
\text { na Saúde do Adulto e do Idoso }\end{array}$ \\
\hline 2002 & $\begin{array}{l}\text { Assistência de } \\
\text { Enfermagem }\end{array}$ & UFMS & $\begin{array}{l}\text { Assistência de enfermagem à saúde do } \\
\text { adulto e idoso }\end{array}$ \\
\hline 2002 & $\begin{array}{l}\text { Grupo de Pesquisa em } \\
\text { Fundamentos de } \\
\text { Enfermagem }\end{array}$ & UFF & $\begin{array}{l}\text { Educação em saúde com clientes idosos e } \\
\text { diabéticos }\end{array}$ \\
\hline 2002 & $\begin{array}{l}\text { Grupo de Pesquisa em } \\
\text { Saúde Coletiva }\end{array}$ & UFTM & Saúde do adulto e do idoso \\
\hline 2002 & $\begin{array}{l}\text { Grupo de Pesquisa } \\
\text { Interdis ciplinar em } \\
\text { Enfermagem em Saúde } \\
\text { Coletiva e } \\
\text { Epidemiologia }\end{array}$ & UFAM & Saúde do idoso na Amazônia ocidental \\
\hline 2002 & $\begin{array}{l}\text { O Cotidiano do Cuidar } \\
\text { em Enfermagem }\end{array}$ & UFJF & $\begin{array}{l}\text { Cuidando do adulto e do idoso: o } \\
\text { cotidiano como espaço de representações }\end{array}$ \\
\hline 2002 & $\begin{array}{l}\text { GAPEDI - Grupo de } \\
\text { Assistência, Pesquisa e } \\
\text { Educação ao Adulto e } \\
\text { ao Idoso }\end{array}$ & UNIOESTE & Práticas saberes e políticas publicas \\
\hline 2004 & $\begin{array}{l}\text { Grupo de Estudos em } \\
\text { Trauma - Emergência e } \\
\text { Cuidados Intensivos }\end{array}$ & UNIFESP & $\begin{array}{l}\text { Fundamentos e práticas de enfermagem na } \\
\text { saúde do adulto e idoso }\end{array}$ \\
\hline 2004 & $\begin{array}{l}\text { Intervenções de } \\
\text { Enfermagem no } \\
\text { Processo Saúde - } \\
\text { Doença }\end{array}$ & UEPA & $\begin{array}{l}\text { Estudos do processo de envelhecimento } \\
\text { saudável }\end{array}$ \\
\hline 2004 & $\begin{array}{l}\text { GEAPE - Grupo de } \\
\text { Estudo sobre a } \\
\text { Assistência de } \\
\text { Enfermagem } \\
\text { Perioperatória }\end{array}$ & USP & $\begin{array}{l}\text { Cuidar do adulto e idoso com afecções } \\
\text { agudas e criticas; Tecnologia na saúde do } \\
\text { adulto e idoso }\end{array}$ \\
\hline 2005 & $\begin{array}{l}\text { GEPECADI - Grupo de } \\
\text { Estudo e Pesquisa em } \\
\text { Enfermagem no } \\
\text { Cuidado ao Adulto e } \\
\text { Idoso }\end{array}$ & UFRGS & $\begin{array}{l}\text { Práticas e cuidado de enfermagem na } \\
\text { saúde do adulto e idoso; Danos críticos } \\
\text { agudos e crônicos do adulto e idoso }\end{array}$ \\
\hline 2005 & $\begin{array}{l}\text { Reabilitação e } \\
\text { Funcionalidade em } \\
\text { Saúde }\end{array}$ & USP & $\begin{array}{l}\text { Envelhecimento e funcionalidade; } \\
\text { Reabilitação e funcionalidade de adultos e } \\
\text { idosos com afecções ortopédicas e } \\
\text { traumatológicas }\end{array}$ \\
\hline 2005 & $\begin{array}{l}\text { Núcleo de Estudos } \\
\text { Interdisciplinaridade } \\
\text { Criativa em } \\
\text { Enfermagem }\end{array}$ & FTC & $\begin{array}{l}\text { Ações interdisciplinares da enfermagem, } \\
\text { família, e cuidador na saúde do adulto e do } \\
\text { idoso }\end{array}$ \\
\hline
\end{tabular}




\begin{tabular}{|c|c|c|c|}
\hline 2005 & $\begin{array}{l}\text { O Cuidar em } \\
\text { Enfermagem e a } \\
\text { Educação em Saúde do } \\
\text { Adulto, do Idoso e do } \\
\text { Trabalhador }\end{array}$ & UNG & $\begin{array}{l}\text { Cuidar em enfermagem; Políticas Públicas } \\
\text { e de Gestão em Serviços de Saúde }\end{array}$ \\
\hline 2005 & $\begin{array}{l}\text { Process o de Cuidar em } \\
\text { Saúde }\end{array}$ & UEMG & $\begin{array}{l}\text { Envelhecimento e saúde do idoso; Saúde } \\
\text { do adulto }\end{array}$ \\
\hline 2005 & $\begin{array}{l}\text { Estudos na Área da } \\
\text { Saúde }\end{array}$ & FEPECS & Enfermagem gerontogeriátrica \\
\hline 2006 & $\begin{array}{l}\text { Condições Crônicas e } \\
\text { suas Interfaces }\end{array}$ & UFPEL & $\begin{array}{l}\text { O idoso e a família no cuidado para a } \\
\text { prevenção, reabilitação e controle das } \\
\text { condiçoes crônicas }\end{array}$ \\
\hline 2006 & $\begin{array}{l}\text { PROCUIDAI - Grupo } \\
\text { de Pesquisa do } \\
\text { Processo de Cuidar do } \\
\text { Adulto e do Idoso }\end{array}$ & UPF & $\begin{array}{l}\text { Cuidado de enfermagem do adul to e do } \\
\text { idoso }\end{array}$ \\
\hline 2006 & $\begin{array}{l}\text { Núcleo de Pesquisa } \\
\text { Cuidado de } \\
\text { Enfermagem no Ciclo } \\
\text { Vital }\end{array}$ & UNICENTRO & $\begin{array}{l}\text { A saúde do adulto e do idoso e o } \\
\text { desenvolvimento das doenças crônicas }\end{array}$ \\
\hline 2007 & $\begin{array}{l}\text { Grupo de Estudos e } \\
\text { Pesquisas em } \\
\text { Epistemologia e } \\
\text { Fundamentos do } \\
\text { Cuidar em Saúde e } \\
\text { Enfermagem }\end{array}$ & UPE & $\begin{array}{l}\text { Políticas e processo do cuidar na saúde do } \\
\text { adulto, idoso e trabalhador }\end{array}$ \\
\hline 2007 & Enf Saúde 03 & UNIMES & $\begin{array}{l}\text { Políticas públicas em saúde na atenção ao } \\
\text { idoso }\end{array}$ \\
\hline 2007 & $\begin{array}{l}\text { GEPASH - Grupo de } \\
\text { Estudos e Pesquisas } \\
\text { Sobre a Assis tência } \\
\text { para a Saúde Humana }\end{array}$ & UFCG & Assistência à saúde do idoso \\
\hline 2008 & $\begin{array}{l}\text { Abordagens } \\
\text { Metodológicas de } \\
\text { Pesquisa Qualitativa na } \\
\text { Área da Saúde }\end{array}$ & UNESP & $\begin{array}{l}\text { Experiências do adulto, idoso, famílias e } \\
\text { equipe de saúde em face ao processo } \\
\text { saúde-doença }\end{array}$ \\
\hline 2008 & $\begin{array}{l}\text { Família, Comunidade e } \\
\text { Enfermagem - Teoria e } \\
\text { Prática }\end{array}$ & UFRJ & Enfermagem e saúde do idoso \\
\hline 2009 & $\begin{array}{l}\text { Grupo de Estudos e } \\
\text { Pesquis a em Saúde do } \\
\text { Adulto e do Idoso }\end{array}$ & UFPB & $\begin{array}{l}\text { Fundamentos teóricos-filosóficos do } \\
\text { cuidar em saúde e enfermagem; } \\
\text { Políticas e práticas em saúde e } \\
\text { enfermagem }\end{array}$ \\
\hline 2009 & $\begin{array}{l}\text { Grupo de Pesquisa, } \\
\text { Ensino e Extensão: } \\
\text { Conhecimentos, } \\
\text { Práticas e Legislação } \\
\text { em Saúde }\end{array}$ & UFMS & $\begin{array}{l}\text { Conhecimentos, práticas e legislação em } \\
\text { saúde do idoso }\end{array}$ \\
\hline 2009 & $\begin{array}{l}\text { Grupo do Cuidar- } \\
\text { Gecen Grupo de } \\
\text { Estudos e Pesquisa } \\
\text { sobre o Cuidar em } \\
\text { Enfermagem }\end{array}$ & UFBA & $\begin{array}{l}\text { O cuidar e o cuidado ao idoso na família, } \\
\text { em serviços saúde e instituições de longa } \\
\text { permanência. }\end{array}$ \\
\hline
\end{tabular}




\begin{tabular}{|l|l|l|l|}
\hline 2009 & $\begin{array}{l}\text { Núcleo de Estudos e } \\
\text { Pesquisas em } \\
\text { Integralidade, } \\
\text { Enfermagem e Saúde }\end{array}$ & UNESC & $\begin{array}{l}\text { O Cuidar em Saúde e Enfermagem do } \\
\text { adulto em seu processo de saúde-doença e } \\
\text { envelhecimento }\end{array}$ \\
\hline 2009 & $\begin{array}{l}\text { NUT ADIES -Núcleo } \\
\text { de Estudos e Pesquisas } \\
\text { em Tecnologias de } \\
\text { Avaliação, Diagnóstico } \\
\text { e Intervenção de } \\
\text { Enfermagem e Saúde }\end{array}$ & UFG & $\begin{array}{l}\text { Tecnologias de avaliação, diagnóstico e } \\
\text { intervenção na área de saúde do adulto e } \\
\text { do idoso }\end{array}$ \\
\hline 2009 & $\begin{array}{l}\text { GEPSAI - Grupo de } \\
\text { Estudo e Pesquisa em } \\
\text { Saúde do Adulto e do } \\
\text { Idoso }\end{array}$ & UNIVASF & Saúde do idoso \\
\hline
\end{tabular}

Fonte: Censo 2006 - Diretório dos Grupos de Pesquisa no Brasil - CNPq. Acesso em 20 mar 2010

Os achados desse estudo demonstram o pioneirismo da pesquisa no desenvolvimento do conhecimento em enfermagem gerontológica. Em ordem cronológica, o primeiro grupo de pesquisa no Brasil foi o Núcleo de Estudos e Pesquisas do Idoso ( NESPI), da Universidade Federal da Bahia, formado em 1973, e que continua atuante na contemporaneidade. A dimensão da importância histórica da criação desse grupo de pesquisa em enfermagem gerontológica aparece em artigo que faz a análise das pesquisas do envelhecimento no Brasil. Há relato do surgimento de oito grupos de pesquisa na área na década de 1970, dos quais apenas um se encontrava especificamente voltado para a temática da saúde do idoso nos aspectos biopsicossociais, Núcleo de Estudos e Pesquisas do Idoso (NESPI), na área de enfermagem, instalado na Universidade Federal da Bahia (UFBA). ${ }^{15}$

Na década seguinte, segundo informações do Diretório de Pesquisas do CNPq, foram formados dois outros grupos: Grupo de Estudos sobre Cuidado de Saúde de Pessoas Idosas (GESPI), da Universidade Federal de Santa Catarina, em 1982; e o Núcleo de Pesquisa de Enfermagem Geriátrica e Gerontológica (NUPEGG), em 1985, na Universidade de São Paulo.

Novamente, a literatura traz o constituinte histórico desses grupos, ao citar que, na década de 1980, foi três vezes maior o número de grupos que contavam com linha de pesquisa relativa ao envelhecimento humano: 24 grupos. Deles, apenas três foram classificados como específicos: um da área de enfermagem, da Universidade Federal de Santa Catarina (UFSC), o Núcleo de Estudos da Terceira Idade (Neti), que constava como o primeiro programa universitário de atendimento ao idoso e de formação de recursos humanos no campo gerontológico; outro também da área de enfermagem da Universidade de São Paulo (USP) de Ribeirão Preto; e, finalmente, o grupo da área de serviço social da Pontifícia Universidade Católica de São Paulo. ${ }^{15}$
Esse é um dado histórico para a enfermagem gerontológica no Brasil. Durante as décadas de 1970 e 1980, só existiam quatro grupos de pesquisa com especificidade do estudo do idoso, e três deles eram da enfermagem. Esse fato demonstra o pioneirismo e a visibilidade que a enfermagem teve na história da construção do processo de envelhecimento, que devem trazer orgulho para a profissão e reconhecimento do papel desses grupos pioneiros na história da gerontologia no Brasil. 0 relato da criação desses grupos é coincidente com a contextualização histórica da década de 1980, quando a CAPES exigiu a vinculação dos grupos de pesquisas a programas de pós-graduação das instituições, possibilitando aos orientandos o ingresso naqueles programas.

Como já citado anteriormente, a criação de grupos de pesquisa sobre o processo de envelhecimento na década de 1980 também foi influenciada pela I Assembléia Mundial sobre o Envelhecimento, de Viena, em 1982. 0 quantitativo reduzido pode induzir ao questionamento de sua relevância; entretanto, dada a temporalidade daquela década, como sendo a época do início do fomento à pós-graduação, em que havia reduzido número de doutores em enfermagem, a formação de três grupos com linha de pesquisa específica do idoso agiganta-se perante as dificuldades encontradas.

Cronologicamente na década de 1990, formaram-se mais três grupos de estudo com linhas de pesquisa sobre 0 processo de envelhecimento. Esse crescimento tímido no número de grupos reflete essa como a década do amadurecimento dos estudos sobre o idoso. Nesse período ocorreu mundialmente a transformação da percepção dos pesquisadores sobre o idoso, a qual saiu da visão de associação do envelhecimento com dependência e problema social, e foi para seu reconhecimento como segmento populacional ativo e atuante, com direito ao bem-estar e à autonomia. ${ }^{16}$ 
Já no início do século XXI ocorreu uma verdadeira explosão quantitativa na formação dos grupos: 33 grupos de pesquisa, quatro deles com especificidade do estudo ao idoso, e 29 grupos com linhas de pesquisa sobre o processo de envelhecimento, com média dessa década em torno de seis novos grupos a cada ano. Esse crescimento vertiginoso está contextualizado nas políticas internacionais: o estabelecimento do Ano Internacional do Idoso em 1999 e da II Assembléia Mundial do Envelhecimento, realizada em Madri, em 2002; bem como na transição demográfica de envelhecimento populacional percebida no aumento dessa faixa etária nos serviços de saúde. 0 incremento quantitativo nos grupos de pesquisa reflete também o aumento da qualificação dos pesquisadores, em geral, e da enfermagem no Brasil. Trabalho realizado sobre as pesquisas e os pesquisadores do processo de envelhecimento ${ }^{15}$ apontou que $65 \%$ dos pesquisadores atuantes no país obtiveram o título de doutor entre 1990 e 1999.

Esse fato está contextualizado no cenário nacional das políticas públicas de incremento à pós-graduação na década de 1990, refletidas nos números de alunos quando o número de matrículas nos mestrados aumentou de 43 mil, em 1994, para 54 mil, em 1999, representando um crescimento de 25\%. Já nos doutorados, em 1994, havia 19 mil alunos, número que aumentou mais de $50 \%$ em 1999, quando foi para 29 mil. ${ }^{17}$ Ao se considerar esses pesquisadores como líderes de grupos e mola propulsora do fomento à pesquisa, encontra-se explicação para o aumento de grupos na enfermagem gerontológica na década presente, que reflete no desenvolvimento da produção científica sobre o processo de envelhecimento.

Apesar desse aumento e da conscientização da necessidade de publicação das pesquisas, cabe aqui o alerta de que ainda é tímido o avanço de publicações sobre essa temática na literatura geral da enfermagem, chegando a 3,7\% delas. Esse número deve despertar os profissionais que atuam na geriatria e gerontologia para a necessidade de desenvolver trabalhos, haja vista as tendências e demandas da prática, que exigem conhecimento específico para atender o segmento idoso da população. ${ }^{18}$

\section{CONSIDERAÇÕES FINAIS}

A compreensão da historicidade do conhecimento em enfermagem gerontológica permitiu obter um panorama ampliado da construção dessa especialidade no Brasil, identificando o grande avanço nas pesquisas sobre 0 processo de envelhecimento na virada do século XXI. A perspectiva da sociologia das profissões de Freidson permitiu a análise do conhecimento como constituinte da autonomia e do poder profissional, ao afirmar que as profissões mais fortes conseguem preservar grande parte do direito de ser árbitro de seu próprio desempenho no trabalho, sob as justificativas de que são as únicas que 0 conhecem o suficiente para avaliá-lo adequadamente e de que estão ativamente comprometidas em garantir que 0 desempenho alcance padrões básicos. ${ }^{5}$

A finalidade deste estudo foi fomentar novos estudos sobre a história da enfermagem gerontológica no Brasil, procurando compreender a construção dela como especialidade. Deve-se compreender que o trabalho final do historiador deve aparecer como um momento de reflexão, e não como um produto acabado. ${ }^{\text {? }}$

Entretanto, este estudo permitiu preliminarmente concluir que o escopo da produção científica em enfermagem sobre o processo de envelhecimento e o número crescente de grupos de estudos interessados nessa temática refletem claramente a evolução desse conhecimento especializado. A Enfermagem Gerontológica no Brasil vem construindo um corpo de conhecimento especializado, que embora necessite de mais esforços no sentido de seu aprimoramento, contextualizado nos avanços teórico-metodológicos em curso, vem utilizando o conhecimento como constituinte de sua prática assistencial.

\section{REFERÊNCIAS}

1.Oliveira CJ, Moreira TMM. Análise das dissertações e teses de enfermagem sobre o idoso, Brasil-1979-2004: estudo bibliográfico. Bras J Nurs [periódico na internet]. 2007; [citado 2008 jul 16]. Disponível em: http:/ /www.uff.br/objnursing/index.php/n

2.Caldas CP, Amorim AE. Os grupos de pesquisa em enfermagem no Brasil e o envelhecimento humano. Rev Cienc Saude. 2004 jan/dez; 23(2): 28-36.

3.Gonçalves LHT, Alvarez AM 0 cuidado na enfermagem gerontogeriátrica: conceito e prática. In: Freitas EV, organizador. Tratado de geriatria e gerontologia. $2^{a}$ ed. Rio de Janeiro(RJ): Guanabara Koogan; 2006. p. 1110-16

4.Santos SMA, Gonçalves LHT. [Editorial]. Texto\&Contexto Enferm. 2008 abr/jun; 17(2): 219-20.

5.Freidson E. Renascimento do profissionalismo: teoria, profecia e política. São Paulo(SP): Edusp; 1998.

6.Padilha MICS, Borenstein MS. 0 método de pesquisa histórica na enfermagem. Rev Texto\&Contexto Enferm. 2005 out/dez; 14 (4): 575-84.

7. Hammerschmidt KSA, Borghi ACS, Lenardt MH, Seima MD. Pesquisas de enfermagem em gerontologia. Cogitare Enferm. 2007 abr/jun; 12(2): 214-21.

8. Eliopoulos C. Enfermagem gerontológica. $5^{\mathrm{a}}$ ed. Porto Alegre (RS): Artmed; 2005. 
9. Achenbaum WA. Crossing frontiers: gerontology emerges as a science. Cambridge (USA): Cambridge University Press; 1995.

10. Vale EG, Pagliuca LMF, Quirino RHR. Saberes e práxis em enfermagem. Esc Anna Nery . 2009 jan/mar; 13 (1): 174-80.

11.Gonçalves LT, Alvarez AM. O cuidado na enfermagem gerontogeriátrica:conceito e prática. In: Freitas EV, et al. Tratado de geriatria e gerontologia. Rio de Janeiro (RJ): Guanbara Koogan;. 2002. p. 756-61.

12. Ministério da Saúde (BR). Lei nº 8.842, de 04 de janeiro de 1994. Dispõe sobre a Política Nacional do Idoso, cria o Conselho Nacional do Idoso e dá outras providências. Brasília (DF); 1994.

13. Rocha FC, Viana BC, Maria SL, Maria, HBA, Figueiredo MLF. Análise da produção científica sobre o idoso na REBEn. Rev Bras Enferm. 2007 jul/ ago; 60(4): 449-51.

14. Victor JF, Vasconcelos FF, Araújo AR, Ximenes LB, Araújo TL. Grupo Feliz Idade: cuidado de enfermagem para a promoção da saúde na terceira idade Rev Esc Enferm. USP. 2007 dez; 41(4): 724-30.

15. Prado SD, Sayd JD. A pesquisa sobre envelhecimento humano no Brasil: pesquisadores, temas e tendências. Cienc Saude Colet. 2004 jul/ set; 9(3): 763-72.

16. Ministério da Saúde (BR). Portaria n 1395, de 10 de dezembro de 1999. Política de Saúde do Idoso. Brasília (DF); 1999.

17. Velloso J, Velho L. Mestrandos e doutorandos no país: trajetórias de formação. Brasília (DF): Fundação de Coordenação de Aperfeiçoamento de Pessoal de Nível Superior; 2001.

18. Veiga KCG, Menezes, TMO. Produção do conhecimento em enfermagem: a (in) visibilidade da atenção à saúde do idoso. Rev Esc Enferm USP. 2008; 42(4): 761-68. 